\title{
Study on Acute Abdomen In HIV Infected Patients
}

\author{
Dr.M.Ramya, Dr.S.Nareshkumar \\ ${ }^{I}$ Dept.Of General Surgery Dept.Of General Surgery \\ ${ }^{2}$ ESIC Medical College \& Hospital ESIC Medical College \& Hospital
}

\begin{abstract}
Aim: To establish the causes of acute abdomen in HIV infected patients, the treatment modalities and outcome of surgical intervention in these patients

Materials And Methods: This is a prospective study on HIV infected patients presenting with acute abdomen to the emergency dept of Gandhi Hospital over a period of 3 years from May 2011 to April 2014.

Results: In our study 114/136 (83.8\%) male patients and 22/136 (16.2\%) female patients are included.

No. of patients operated 85 (62.5\%) and conservatively treated 51 ( $37.5 \%)$

Appendicitis (including perforation) is the most common cause of acute abdomen in HIV positive patients constituting $23.5 \%$ of total cases.

Conclusion: $\mathrm{CD}_{4}$ count was a significant prognostic factor deciding postoperative recovery of patients. Asymptomatic HIV-infected patients recover well from surgery and do not appear to suffer delayed healing. ${ }^{11}$

Laparoscopy might be an important tool in the evaluation of these patients with acute abdomen which can overcome the diagnostic dilemma and ensure an effective management ${ }^{14}$
\end{abstract}

\section{Introduction}

The prevalence of human immunodeficiency virus (HIV) infection is rising at an exponential rate. The HIV patient presents with a variety of abdominal conditions, some of which are frequent amongst the immunocompetent population, while others are directly HIV related. Complexity in the interpretation of clinical findings leads to delayed diagnosis and treatment. Since the initial descriptions of HIV and AIDS-defining illnesses, many reports have validated the safety of abdominal surgery in the HIV/AIDS patient. ${ }^{(1-8)}$ Immune status has been implicated as a marker of potential outcome in patients with HIV/AIDS. The introduction ofhighly active antiretroviral therapy (HAART) in the mid-1990s heralded a new era in the treatment of HIV/AIDS.The impact of HAART on surgical outcomes has beenshown to be protective in some series ${ }^{(9)}$ but without overall improvement in others. ${ }^{(10)}$

\section{Materials And Methods}

Study design: This is a prospective study

Study setting: HIV infected patients presenting with acute abdomen to the emergency dept of Gandhi Hospital over a period of 3 years from May 2011 to April 2014.

Inclusion criteria: All seropositive HIV cases requiring emergency major surgical operations in the age group of 14 - 60 years including those on HAART and those diagnosed during present evaluation were included. Exclusion criteria: co-morbid illness like diabetes mellitus, asthma, CAD, cancer, HBsAg +ve, gynaecological conditions.

Protocol: A total of 136 patients have been included in the study. A detailed history was taken and thorough clinical examination was done. Then we proceeded with investigations which included radiological investigations like X-ray abdomen, USG abdomen and pelvis, Chest X-ray, CT scan abdomen (if required).Serological investigations included complete blood picture, blood sugar, renal function tests, liver function tests, S.amylase, S.lipase, viral screening, CD4 count.

Data analysis: Data was analysed using chi-square test. Tables and figures were used to show the distribution of factors in the two groups.

Ethical considerations: Patients for emergency major surgery were reviewed in the emergency surgical ward and written informed consent obtained for the study, for HIV test and for the operation. Approval for the study was taken from ethics committee of Gandhi Hospital.

\section{Results}

A total of 136 patients recruited over a 3year period had emergency major surgery in Gandhi hospital emergency theatre. Comparison of demographic characteristics of patients inthe study There were 8 patients between 15- 24 years, 59 patients between 25-34 years, 33 patients between 35-44 years, 27 between 45-54 years and 9 patients between 55-64years. The group with the highest infection was the 25-34 year age group. There were $114 / 136(83.8 \%)$ male patients and 22/136 (16.2\%) female patients. 
Table 1: Age demographics

\begin{tabular}{|l|l|}
\hline Age group & No. of patients \\
\hline $15-24$ & 8 \\
\hline $25-34$ & 59 \\
\hline $35-44$ & 33 \\
\hline $45-54$ & 27 \\
\hline $55-64$ & 9 \\
\hline
\end{tabular}

Table 2: Diagnosis

\begin{tabular}{|c|c|c|c|}
\hline \multirow[t]{2}{*}{ S.no. } & \multirow[t]{2}{*}{ Diagnosis } & \multicolumn{2}{|c|}{ No. of patients } \\
\hline & & Operated & Conservative \\
\hline 1 & RIF pain & 36 & 7 \\
\hline a) & Acute appendicitis & 22 & - \\
\hline b) & Acute appendicular perforation & 10 & - \\
\hline c) & Acute mesenteric adenitis & 2 & 3 \\
\hline d) & Ileitis & 2 & 4 \\
\hline 2 & $\begin{array}{l}\text { Peritonitis due to hollow viscus } \\
\text { perforation }\end{array}$ & 33 & - \\
\hline a) & Peptic ulcer perforation & 12 & - \\
\hline b) & Ileal perforation & 21 & - \\
\hline 3 & Intestinal obstruction & 13 & 6 \\
\hline a) & Sigmoid volvulus & 1 & - \\
\hline b) & TB & 3 & 2 \\
\hline c) & Post op adhesions & 3 & 4 \\
\hline d) & Band & 4 & - \\
\hline e) & Rectosigmoid growth & 2 & - \\
\hline 4 & Ruptured liver abscess & 3 & - \\
\hline 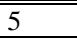 & Renal colic & 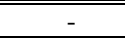 & 19 \\
\hline 6 & Acute pancreatitis & 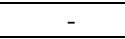 & 13 \\
\hline 7 & Acute cholecystitis & - & 6 \\
\hline a) & Calculouscholecystitis & - & 5 \\
\hline b) & Acalculouscholecystitis & - & 1 \\
\hline
\end{tabular}

Table 3: Treatment modality

\begin{tabular}{|l|l|}
\hline No. of patients operated & $85(62.5 \%)$ \\
\hline Conservative & $51(37.5 \%)$ \\
\hline
\end{tabular}

Table 4: ? ART induced complications

\begin{tabular}{|l|c|c|}
\hline Diagnosis & On ART & ?Drug induced \\
\hline Acute pancreatitis & 4 & 1 \\
\hline Renal colic & 6 & 2 \\
\hline
\end{tabular}

Table 5: Postoperative complications

\begin{tabular}{|l|l|l|l|l|l|}
\hline S.no. & Complications & No. of patients & \\
\hline \multicolumn{2}{|l|l|l|l|}{} & Total & $\mathrm{CD}_{4}<200$ & $>200$ & $\mathrm{P}$ \\
\hline 1 & Wound infection & 26 & 10 & 16 & $<0.01$ \\
\hline 2 & Respiratory infection & 8 & 6 & 2 & 0.02 \\
\hline 3 & UTI & 4 & 2 & 2 & $>0.1$ \\
\hline 4 & Leak & 8 & 5 & 2 & 0.02 \\
\hline
\end{tabular}

Table 6: Hospital stay

\begin{tabular}{|c|c|c|c|c|}
\hline Hospital stay & Total & $\mathrm{CD}_{4}<200$ & $>200$ & $\mathrm{P}$ \\
\hline$\leq 10$ days & 56 & 8 & 48 & \\
\hline$>$ 10days & 23 & 9 & 14 & $<0.05$ \\
\hline Mortality & 6 & 4 & 2 & \\
\hline
\end{tabular}




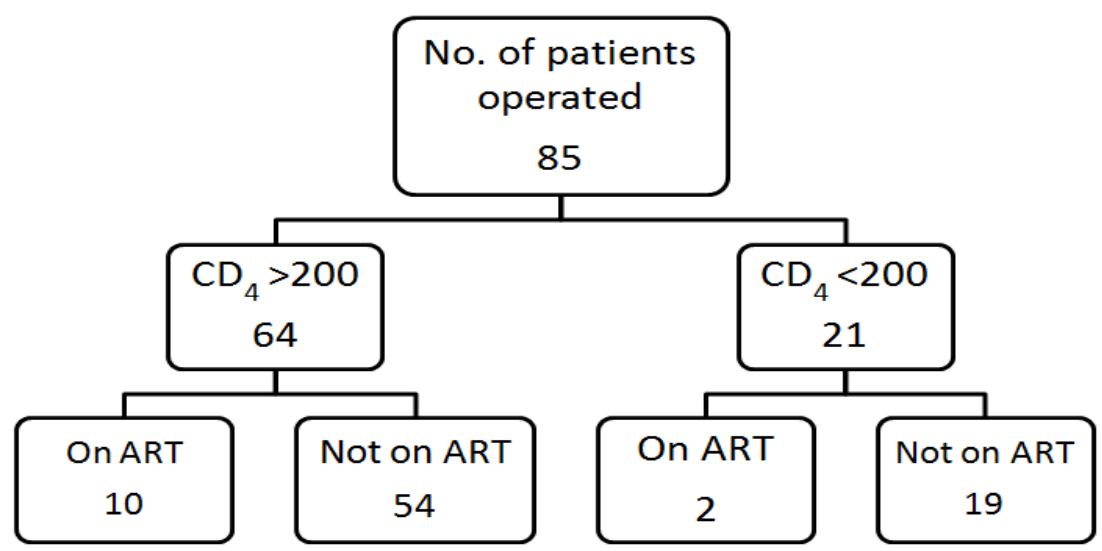

\section{Discussion}

Abdominal pain in the HIV-infected patient is a difficult diagnostic and therapeutic problem. Many HIV infectedpatients complain of abdominal pain during the course of their illness. A large proportion of such complaints are caused by organomegaly, lymphadenopathy, opportunistic enteric infections and spontaneous bacterial peritonitis which do not require surgery. The surgeon's dilemma is in differentiating these conditions from surgically treatable pathology. Of the total 136 patients with acute abdomen, $62.5 \%$ cases were operated and $37.5 \%$ were managed conservatively. Out of those 85 operated cases, there were 6 cases with difficult diagnosis, which could have probably been managed conservatively ( 2 cases of ileitis, 2 mesenteric adenitis, 2 TB abdomen). Appendicitis (including perforation) is the most common cause of acute abdomen in HIV constituting $23.5 \%$ of total cases.

$\mathrm{CD}_{4}$ count was a significant prognostic factor deciding post operative recovery of patients. Complications occurred in $10(47.6 \%)$ cases with $\mathrm{CD}_{4}$ count $<200$ while in 17 (26.6\%) cases with $>200$ count. The overall incidence of postoperative complications during open surgeries was $25 \%{ }^{13,14}$. Asymptomatic HIVinfected patients recover well from surgery and do not appear to suffer delayed healing. ${ }^{11,12}$

High mortality and morbidity rates had been reported in various studies on abdominal surgery in HIV-infected patients. ${ }^{6}$ Our mortality rate of $7 \%$ (6 out of 85 ) is much lower than reported rates of $19 \%$ to $48 \%$ in AIDS patients. Acceptable morbidity and mortality rates are achievable in this immunocompromised group as we see in normal patients. Laparoscopy might be an important tool in the evaluation of these patients with acute abdomen which can overcome the diagnostic dilemma and ensure an effective management ${ }^{14}$

\section{References}

[1]. Gottlieb MS, Schroff R, Schanker HM, et al. Pneumocystis carinii pneumonia and mucosal candidiasis in previously healthy homosexual men: evidence of a new acquired cellular immunodeficiency. N Engl J Med 1981;305:1425-31.

[2]. Potter DA, Danforth DN Jr, Macher AM, et al. Evaluation of abdominal pain in the AIDS patient. Ann Surg 1984;199:332-9.

[3]. Wilson SE, et al. Acquired immune deficiency syndrome (AIDS). Indications for abdominal surgery, pathology, and outcome. Ann Surg 1989;210:428-33.

[4]. Robinson G, Wilson SE, Williams RA. Surgery in patients with acquired immunodeficiency syndrome. Arch Surg 1987;122:170 5 .

[5]. Nugent P, O'Connell TX. The surgeon's role in treating acquired immunodeficiency syndrome. Arch Surg 1986;121:1117-20.

[6]. Burack JH, Mandel MS, Bizer LS. Emergency abdominal operations in the patient with acquired immunodeficiency syndrome. Arch Surg 1989;124:285- 6.

[7]. Deziel DJ, Hyser MJ, Doolas A, et al. Major abdominal operations in acquired immunodeficiency syndrome. Am Surg 1990;56:445-50.

[8]. Vipond MN, Ralph DJ, AT. Stotter, Surgery in HIV-positive and AIDS patients: indications and outcome. J R CollSurgEdinb 1991; 36:254-8.

[9]. Foschi D, Cellerino P, Corsi F, et al. Impact of highly active antiretroviral therapy on outcome of cholecystectomy in patients with human immunodeficiency virus infection. Br J Surg 2006;93:1383-9.

[10]. Horberg MA, Hurley LB, Klein DB, et al. Surgical outcomes in human immunodeficiency virus-infected patients in the era of highly active antiretroviral therapy. Arch Surg 2006;141:1238-45.

[11]. Ming K Y, Saunder A, Scott D F. Abdominal surgery in HIV/AIDS patients: Indications, operative management, pathology and outcome. Aust N Z J Surg 1995; 65:320-6.

[12]. Buehrer J L, Weber D J, Meyer A A. Wound infection rates after invasive procedures in HIV-1 seropositive versus HIV-1 seronegative hemophiliacs. Ann Surg 1990; 211:492-8.

[13]. Rose, David N. I, 4; Collins, Megan 2; Kleban, Rebecca 3.Complications of surgery in HIV-infected patients.AIDS. 12(17):224351, November 1998.

[14]. Emparan C, Iturburu IM, Portugal V, Apecechea A, Bilbao JE, Méndez JJ. Infective complications after minor operations in patients infected with HIV: role of CD4 lymphocytes in prognosis. EurJSurg 1995; 161:721-723.

[15]. VijaykumarRajaramNaik. The role of Laparoscopic Surgery in the Surgical Treatment of HIV Patients. World Journal of Laparoscopic Surgery, May-August 2008;1 (2):9-14 